\title{
ASSESSING THE IMPACT OF AMBIENT OZONE ON GROWTH AND YIELD OF CROP AT RAMPUR, CHITWAN
}

K. Kharel ${ }^{1}$ and L. P. Amgain ${ }^{2}$

\begin{abstract}
An experiment was conducted at Institute of Agriculture and Animal Science, Rampur, Chitwan, Nepal during March-July 2008 to explore the impact of ambient ozone on crop growth and yield. Mungbean cultivar "Pratikshya" was used as a test crop for the study. Mungbean plants were planted in 40 pots and $50 \%$ of the plants (i.e. plants in 20 pots) were treated with ethylenediurea (EDU) from 13 DAS to crop maturity at 10 days intervals. The ambient ozone level of the site was measured with passive samplers. The ozone level ranged from 29.3 to $39.1 \mathrm{ppb}$ at the experimentation site during the cropping period. It was found that the ambient ozone at the site caused significant effects on plant growth and yield. The observed ambient ozone was found to reduce the growth parameters like plant height, per plant number of leaves, and number of branches by $10 \%, 27.74 \%$, and $10.88 \%$, respectively at 70 DAS while it reduced per plant number of seeds $(13.17 \%)$, seed dry weights (19.67\%), test weight (g/1000 seeds), (10.28\%), total above-ground biomass (16.60\%), harvest index (6.25\%), and shelling percentage (5.07\%) of controlled over EDU treated plants (ozone protected). The study clearly indicated that ambient ozone contributes to lower plant growth and crop yield.
\end{abstract}

Key words: Ambient ozone, ethylenediurea (EDU), passive sampler

\section{INTRODUCTION}

Ambient ozone is both an air pollutant and a greenhouse gas (Tonneijck and Van Dijk, 1997). Its concentrations have doubled since pre-industrial times, with average annual concentrations ranging from 20 to $45 \mathrm{ppb}$ in the major parts of the world (Booker, 2007). In Asia, its concentration is alarmingly high with severe 03 episodes of $90-200 \mathrm{ppb}$ in some large metropolitan areas of many countries (Emberson, 2007).

Ambient ozone is assumed to be the most important phyto-toxic air pollutant (US EPA, 1996; cited in Elagoz and Manning, 2002) and causes more damage to plants than all other air pollutants combined (USDA, 2000). Effects of elevated 03 concentration include a decrease in plant growth and an alternation in plant metabolism that would ultimately reduce the crop yield (Emberson et al., 2003). Furthermore, 03 sensitive plants frequently exhibit visible foliar injury, and also reduction in nutritional quality in some crops and forages (Booker, 2007). These effects may be due to effect of 03 in physiological processes of plants such as stomatal functioning, photosynthesis, respiration, and translocation of photosynthates (Chappelka and Chevone, 1992; Skarby et al., 1998; Musselman and Massman, 1999; cited in Kainulainen et al., 2000).

Emberson and Büker (2008) reported that current day concentrations of ground level 03 are commonly reducing crop yields by $5-35 \%$ of agriculturally important locations across south Asia. Since Nepal is sandwiched between two giant industrial nations, India and China, the ambient ozone concentration could have been contributed to lower crop yield in the country. But, no in-depth studies have been conducted in Nepal yet to assess effect of ambient ozone on crop yield.

\footnotetext{
${ }^{1}$ M.Sc. Agriculture, Ph. 12542923513, Email: kabboo17@yahoo.com

${ }^{2}$ Assistant Professor, IAAS, Rampur Chitwan, Email: Ip_amgain@rediffmail.com
} 
This study was an initiative on impact study of ambient ozone in Nepal. During the study, ambient ozone at the research site was measured and its effects were monitored on mungbean, an important summer crop in Nepal.

\section{MATERIALS AND METHODS}

The experiment was carried out at the Institute of Agriculture and Animal Science (IAAS), Rampur, Chitwan. It is situated at $27^{\circ} 37^{\prime} \mathrm{N}, 84^{\circ} 25^{\prime} \mathrm{E}$ and about 256masl. The duration of study was from March to July 2008 (while actual cropping duration was April-June). The air temperature and relative humidity of the research site were measured with Tinytag (a data logger). The passive samplers (5 pairs provided by IVL Laboratory, Sweden) were used to measure the ozone concentration integrated over time. Approximately 10 liter volume pots with a $25 \mathrm{~cm}$ surface diameter and $30 \mathrm{~cm}$ height were used for experimentation. Approximately $8.5 \mathrm{~kg}$ of soil-mix (local soil: sand: compost $=1: 1: 1$ ) was used per pot. The composite sample was analyzed at Soil Management Directorate, Hariharbhavan, Lalitpur, Nepal. The result of the test is presented in Table 1.

Table 1: Soil used in experiment (2008)

\begin{tabular}{lll}
\hline Details & Results & Remarks \\
\hline $\mathrm{pH}$ & 5.5 & Acidic \\
$\mathrm{N}(\%)$ & 0.13 & Medium \\
$\mathrm{P}_{2} \mathrm{O}_{5}\left(\mathrm{~kg} \mathrm{ha}^{-1}\right)$ & 67 & High \\
$\mathrm{K}_{2} \mathrm{O}\left(\mathrm{kg} \mathrm{ha}^{-1}\right)$ & 298 & High \\
Organic Matter $(\%)$ & 2.6 & Medium \\
\hline
\end{tabular}

Approximately $30 \mathrm{~g}$ locally available fertilizer Samadhan (NPK in the ratio of 19:19:19) and $1 \mathrm{~g}$ micronutrient $\mathrm{MgO}$ were mixed in the soil and applied in each pot for balanced nutrient supply. Each pot was provided with three fiberglass wicks extending to the water reservoirs below them. This method of watering plants was applied to check the rapid downward movements of EDU during irrigation.

On April 7 2008, three seeds of mungbean cultivar "Pratikshya" were sown per pot. At 10 DAS, they were thinned to one plant per pot. Thus, only one plant per pot was exposed to ambient ozone in the field. At 13 DAS, $50 \%$ of the plants (i.e. alternate 20 pots) were treated with $100 \mathrm{ml}$ of $400 \mathrm{ppm}$ freshly prepared EDU solution in distilled water. The EDU application was repeated in every 10 days until the maturity of reproductive parts with an increasing volume of $50 \mathrm{ml}$ at every 20 days. Controlled plant was treated with the similar volume of only distilled water.

Weeds were removed from the pots and around the pots as necessary throughout the experimental period. Watering was done through the fiberglass wicks that were projected into the water reservoir (water bucket) and through natural rainfall. As plant protection measures, organic pesticide "Azadaractin" and "Servo" were applied because they were supposed to have neutral interactions with ozone. Harvesting of mungbean was done when pods were turned brown. Three pickings were done within a week period.

Plant heights, per plant number of leaves, and branches of both control and EDU treatments were recorded at 40,50, 60, and 70 DAS while yield parameter were calculated at crop harvest.

The data recorded on different parameters were analyzed with paired t-test using SPSS software program.

\section{RESULTS AND DISCUSSION}

\section{AMBIENT OZONE AND METEOROLOGICAL RECORDINGS}

Ambient ozone concentration accumulated over time, maximum and minimum air temperature, and the relative humidity data for the experimental period are presented in Fig.1. 
The ambient ozone level was measured at 28 days interval. Highest level of mean ozone concentration (39.1ppb) was observed during April 27 to May 24 and lowest level (17.1ppb) was observed during June 22 to July 192008 . However, 29.3 to $39.1 \mathrm{ppb}$ of ambient ozone level were recorded during crop period (April - June, 2008) This study clearly shows that the periods with high temperature, long sunshine hours, less rainfall, and minimum RH

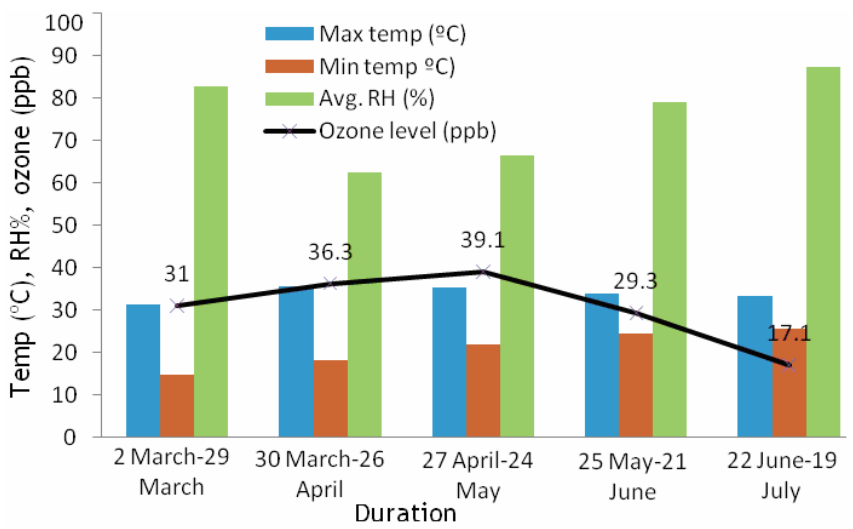
favor the highest level of ozone concentration. This is consistent with the finding of Agrawal et al. (2005) who reported that the high temperature with long light duration favored $\mathrm{O} 3$ formation due to long range transport of ozone precursors. Similarly, USDA (2000) observed high concentrations of ozone during calm, sunny, spring and summer days.

Fig.1: Ambient ozone and meteorological recordings during experimental period (2008)

\section{PLANT GROWTH ATTRIBUTES}

Mean plant height, per plant mean number of leaves, and the mean number of branches of mungbean under control (Non EDU), and EDU treatments during different observations are shown in the Table 2.

Table 2: Measurement of growth parameters of mungbean (Mean \pm S.E.) (2008)

\begin{tabular}{llll}
\hline Days after sowing (DAS) & Control & EDU treated & \% reduced due to ambient ozone \\
\hline Plant height & & & \\
40 & $30.80 \pm 1.25$ & $32.50 \pm 1.19$ & 5.23 \\
50 & $36.86 \pm 1.10$ & $41.14 \pm 1.22^{*}$ & 10.40 \\
60 & $39.64 \pm 1.16$ & $44.02 \pm 1.17^{*}$ & 9.95 \\
70 & $40.41 \pm 1.23$ & $44.90 \pm 1.13^{*}$ & 10 \\
\hline No of leaves/plant & & & \\
40 & $29.35 \pm 1.14$ & $31.05 \pm 1.11$ & 5.47 \\
50 & $35.65 \pm 1.75$ & $40.35 \pm 1.60^{*}$ & 11.64 \\
60 & $32.20 \pm 2.26$ & $39.85 \pm 1.94^{* *}$ & 21.33 \\
70 & $28.00 \pm 2.18$ & $38.75 \pm 2.47^{* *}$ & 27.74 \\
\hline No of branches/plant & & & \\
40 & $4.00 \pm 0.27$ & $4.15 \pm 0.22$ & 3.61 \\
50 & $5.95 \pm 0.34$ & $6.50 \pm 0.32$ & 8.46 \\
60 & $7.45 \pm 0.39$ & $8.35 \pm 0.30$ & 10.77 \\
70 & $8.60 \pm 0.31$ & $9.65 \pm 0.25^{*}$ & 10.88
\end{tabular}

Significant differences between control and EDU treatment are indicated as: ${ }^{*}=p<0.05$ and ${ }^{* *}=p<0.01$

Plant height

No significant difference in plant height was observed during earlier plant growth period. However, significant difference in plant height (i.e. higher plant height) was observed after 
50 DAS onwards with EDU treated plant than control $(p<0.05)$. At 50 DAS, plant height was reduced by $10.40 \%$ in control plants than in EDU treated plants. At 60 DAS and 70 DAS, the plant heights were lesser by $9.95 \%$ and $10 \%$, respectively in control than in EDU treatments. At the crop maturity, the reductions in plant height in control compared to EDU were smaller than expected. This fact may be due to the breakage of tips of some plants at later stages of growth. However, almost $10 \%$ reduction was noticed even at 60 DAS and 70 DAS. It is clear that EDU played significant role to lessen ozone effect in EDU treated plants while control plants were affected by ambient ozone.

Agrawal et al. (2005) also reported similar findings under ambient conditions. They reported $12.3 \%$ increase in plant height of EDU-treated mungbean at 80 DAS in the experiment carried under ambient conditions in India. They also reported significant difference in plant height at later stages compared to early stages. Increased response of plants with time on compounding of the ozone effect could be the reason for this as reported by Morgan et al. (2003).

\section{Number of leaves per plant}

The number of leaves per plant was almost similar in both EDU treated and control plants up to 40 DAS. But, there was significant difference between the number of leaves of control and EDU plants after 50 DAS. Percent reduction in control plants were $5.47 \%, 11.64 \%$, $21.33 \%$ and $27.74 \%$ compared to EDU treated plants at 40, 50, 60 and 70 DAS, respectively. This decreased numbers of leaves per plant in control plants might be due to the effects of ozone whereas the increasing trend in percent reduction might be due to the cumulative action of EDU on plants to build up counter-ozone quality. Similar findings were reported by Tonneijck and Van Dijk, (1997). They reported less number of leaves of Trifolium subterraneum on ozone exposure but higher number of leaves with the application of EDU.

Further, lesser numbers of leaves were noticed per plants at 60 and 70 DAS in both control and EDU treatments; however, severe losses of leaves were observed in control plants. This decreased numbers of leaves in control plant (Non-EDU) may be due to severe senescence during the later stage of plant life as stated by Booker (2007). He reported leaf senescence as one of the most common effects of ambient ozone in plants. Harti et al. (1995) found defoliation of leaves was relatively earlier in non EDU plants than EDU plants of Phaseolus vulgaris L.

\section{Number of branches per plant}

During 40 to 60 DAS, the mean numbers of branches per plant in EDU treated plants were higher than in control plants though they were not statistically different $(p>0.05)$. But, the mean numbers of branches per plant in EDU treated plants was significantly higher at 70 DAs than in control plants $(\mathrm{p}<0.05)$. It was noticed that ambient ozone reduced the number of branches of control plants by $3.61 \%, 8.41 \%, 10.77 \%$ and $10.88 \%$ at $40,50,60$, and 70 DAS, respectively. Manning et al. (2004) also reported lower number of branches in apple trees grown at high ozone level.

\section{Root dry weight}

Dry roots of each plant of both the control and EDU treatments were weighed at final harvest. The observations are shown in Table 3. The mean root dry weight was observed significantly higher in EDU treated plants compared to control $(\mathrm{p}<0.05)$. It might be due to effect of EDU on plants as reported by Harti, et al. (1995) in bean (Phaseolus vulgaris L.) in open-top field chambers experiment. While, in contrast, Perera and Wijesooriya (2007) reported slightly higher root dry weight in Non-EDU plants of mungbean under ambient conditions. They also added that plants under any stress conditions may increase their root biomass as a mechanism for better survival. 
Different yield parameters: per plant number of seeds, seed dry weight, seed test weight, above ground biomass, harvest index $(\mathrm{HI})$ and shelling percent of both control and EDU treated plants were observed at harvest and are presented in Table 4.

Seed dry weights per plant and above ground biomass were highly significant in EDU treated plants than control $(\mathrm{p}<$ 0.01). Also, the number of seeds per plant and shelling percentage were significant $(p<0.05)$ in EDU treatment compared to control. Besides, the

Table 3: Mean root dry weight (g) of mungbean plant at final harvest (Mean \pm S.E.) (2008)

\begin{tabular}{lll}
\hline Parameters & Control & EDU treated \\
\hline Dry root weight & $1.22 \pm 0.05$ & $1.42 \pm 0.04^{*}$ \\
CV\% & 20.68 & 14.63 \\
\hline
\end{tabular}
harvest index was found at par between treatments. The mean number of seeds per plant, dry weight of seeds per plant and test weight of seeds were reduced by $13.17 \%, 19.67 \%$, and $10.28 \%$, respectively in control plants over EDU treated ones.

Fumagalli et al. (2001) reported $17-39 \%$ yield loss in crops such as wheat, bean, watermelon and tomato in ambient conditions. Increment in the number of seeds per plant in EDU treated plants further suggested a protective role of EDU under elevated $\mathrm{O} 3$ levels. Wahid et al. (2001) reported that EDU treatment increased $47 \%$ and $94 \%$ in seed weight per plant in soybean (Glycine max L.) at the sub-urban sites and at the rural sites of Punjab, Pakistan. Similarly, test weight of mungbean plant at ambient ozone was found to be increased by $25.3 \%$ in EDU treated plants over control ones (Agrawal et al., 2005). Tiwari et al. (2005) have reported an improvement of seed yield in wheat (Triticum aestivum L) by applying EDU under ambient conditions.

Total above-ground Table 4: Measurement of yield parameters of mungbean (Mean \pm S.E.) (2008)

\begin{tabular}{|c|c|c|c|}
\hline Yield Parameters & Control & EDU treated & $\begin{array}{l}\text { \% Reduced due to } \\
\text { ambient ozone }\end{array}$ \\
\hline No of seeds/plant & $173.35 \pm 9.25$ & $\begin{array}{ll}199.65 & \pm \\
6.47^{*} & \end{array}$ & 13.17 \\
\hline Seed dry weight/plant (g) & $5.92 \pm 0.28$ & $7.37 \pm 0.23^{* *}$ & 19.67 \\
\hline Test weight of seed (g) & 33.15 & 36.95 & 10.28 \\
\hline Above ground biomass (g) & $18.98 \pm 0.58$ & $22.76 \pm 0.67^{* *}$ & 16.60 \\
\hline Harvest Index (HI) & $0.30 \pm 0.01$ & $0.32 \pm 0.01$ & 6.25 \\
\hline Shelling\% & $63.81 \pm 0.93$ & $67.22 \pm 0.64^{*}$ & 5.07 \\
\hline
\end{tabular}

Sig.nificant difference between treatment sis indicated by ${ }^{*}(p<0.05)$ and ${ }^{* *}(p<0.01)$

biomass of each plant, harvest index and shelling percent were reduced by $16.60 \%, 6.25 \%$ and $5.07 \%$, respectively in control plants over EDU treated. It might be due to higher ambient ozone level at the site. Krupa et al. (2001) found depressed plant biomass due to high ozone. Harti et al. (1995) also found that the increased 03 concentration significantly decreased shoot biomass of Phaseolus vulgaris L. whereas EDU treated plants had higher biomass than control ones. Similarly, Astorino et al. (1995) reported 57 \% reduction in the total above-ground biomass on bean (Phaseolus vulgaris L.) near-ambient level of ozone. Moreover, he suggested that increment in number of pods and seeds/pod and test weight due to EDU-treatment contributed to higher harvesting index of EDU treated plants as compared to control ones.

\section{CONCLUSION}

This study suggests that the ambient ozone at Rampur, Chitwan is high enough to cause significant loss on growth and yield of mungbean. However, different crops may have different responses to ambient ozone. Ozone level measurements at different locations across the country and impact study in different crops may reveal the actual scenarios of ambient ozone level and its impacts in Nepal.

\section{REFERENCE}

Agrawal, S. B., A. Singh and D. Rathore. 2005. Role of ethylenediurea (EDU) in assessing impact of ozone on Vigna radiata L. plants in a suburban area of Allahabad (India). Chemosphere, 61 (2): 218-228. 
Astorino, G., I. Margani, P. Tripodo and F. Manes. 1995. The response of Phaseolus vulgaris L. Cv. Lit. to different dosages of the anti-ozonant ethylenediurea (EDU) in relation to chronic treatment with ozone. Plant Science, 111 (2): 237-248.

Booker, F. 2007. Ambient ozone impacts on specialty crops. Retrieved August 23, 2009, from NC State University web site: www.ncsu.edu/.../usda.../SpecialtyCrops\&O3NE 1030\%20071227.doc.

Elagoz V. and W. J. Manning. 2002. Ozone and bean plants: morphology matters. Environmental Pollution, 120 (3): 521-524.

Emberson, L. 2003. Air pollution impacts on crops and forest: Introduction. Retrieved August 17, 2009, from: http://www.worldsscibooks.com/etextbook/p244_chap1_pdf.

Emberson, L. 2007. Ground level ozone in the $21^{\text {st }}$ century: submission of evidence from the Air Pollution Crop Effect Network (APCEN). Retrieved August 17, 2009, from http://isebindia.com/05_08/07-10-2.html.

Emberson, L. and P. Büker. 2008. Ozone: a threat to food security in South Asia: Policy Brief. Stockholm Environment Institute. Retrieved August 27, 2009, from http://www.sei.se

Fumagalli, I., B. S. Gimeno, D. Velissariou, L. D. Temmerman and G. Mills. 2001. Evidence of ozone-induced adverse effects on crops in the Mediterranean region. Atmospheric Environment, 35(14): 2583-2587.

Harti, S. B., A. Fangmeier and H. J. Jager. 1995b. Influence of ozone and ethylenediurea (EDU) on growth and yield of bean (Phaseolus vulgaris L.) in open-top field chambers. Environmental Pollution, 90(1): 89-94.

Kainulainen, P., J. K. Holopainen, and T. Holopainen. 2000. Combined effects of ozone and nitrogen on secondary compounds, amino acids, and aphid performance in Scots pine. J. Environ. Qual., 29:334-342.

Krupa, S. V., M. T. Mc Grath, C. P. Anderson, F. L. Booker, K. O. Burkey, A. H. Chappelka, B. I. Chevone, E. J. Pell and B. A. Zilinskas. 2001. Ambient ozone and plant health. Plant Disease, 85(1): 4-12.

Manning, W. J., D. R. Cooley, A. F. Tuttle, M. A. Frenkel, and C. J. Bergweiler. 2004. Assessing plant response to ambient ozone: growth of young apple tree in open-top chamber and corresponding ambient air plots. Environmental Pollution, 132(3): 503-508.

Morgan, P. B., E. A. Ainworths and S. P. Long. 2003. How does elevated ozone impact soybean? a metaanalysis of photosynthesis, growth and yield. Plant, Cell and Environment, 26(8): 1317-1328.

Perera A. and S.M. Wijesooriya. 2007. Investigation of the impact of tropospheric ozone on mungbean in Peradeniya, Sri-lanka using EDU. Paper presented in the regional training workshop on the air pollution effect on crop organized by DOE, Ministry of Environment and Forest, Government of Bangladesh and Sweden Environmental Institute. 15-16 August, 2007. Bangladesh.

Tiwari, S., M. Agrawal, W. J. Manning. 2005. Assessing the impact of ambient ozone on growth and productivity of two cultivars of wheat in India using three rates of application of ethylenediurea (EDU). Environmental Pollution, 138(1): 153-160.

Tonneijck, A. E. G. and C. J. van Dijk. 1997. Assessing effects of ambient ozone on injury and growth of Trifolium subterraneum at four rural sites in the Netherlands with ethylenediurea (EDU). Agriculture, Ecosystems and Environment, 65(1): 79-88.

USDA, 2000. Effects of ozone air pollution on plants. Retrieved May 29, 2008 from United States Department of Agriculture web site http://www.ars.usda.gov/Main/docs.htm? docid=12462.

Wahid, A., E. Milne, S. R. A. Shamsi, M. R. Ashmore and F. M. Marshall. 2001. Effects of oxidants on soybean growth and yield in the Pakistan Punjab. Environmental Pollution, 113(3):271-280.

\section{ACKNOWLEDGEMENT}

The research fund awarded by Global Future Institute, USA is highly acknowledged. It's our pleasure to express sincere thanks to Prof. Dr. Patrick Bucker, University of York, UK for his valuable suggestions and help in passive sampler analysis. 